CHRONIC OBSTRUCTIVE PULMONARY DISEASE

\title{
Association between chronic obstructive pulmonary disease and systemic inflammation: a systematic review and a meta- analysis
}

\author{
W Q Gan, S F P Man, A Senthilselvan, D D Sin
}

Thorax 2004;59:574-580. doi: 10.1136/thx.2003.019588

See end of article for authors' affiliations

.....................

Correspondence to: Dr D D Sin, James Hogg iCAPTURE Center for Cardiovascular and Pulmonary Research, St Paul's Hospital, Room 368A, 1081 Burrard Street, Vancouver, BC, Canada V6A 1Y6; dsin@mrl.ubc.ca

Received

28 November 2003

Accepted 29 March 2004
Background: Individuals with chronic obstructive pulmonary disease (COPD) are at increased risk of cardiovascular diseases, osteoporosis, and muscle wasting. Systemic inflammation may be involved in the pathogenesis of these disorders. A study was undertaken to determine whether systemic inflammation is present in stable COPD.

Methods: A systematic review was conducted of studies which reported on the relationship between COPD, forced expiratory volume in 1 second $\left(\mathrm{FEV}_{1}\right)$ or forced vital capacity (FVC), and levels of various systemic inflammatory markers: C-reactive protein (CRP), fibrinogen, leucocytes, tumour necrosis factor- $\alpha$ (TNF- $\alpha$ ), and interleukins 6 and 8 . Where possible the results were pooled together to produce a summary estimate using a random or fixed effects model.

Results: Fourteen original studies were identified. Overall, the standardised mean difference in the CRP level between COPD and control subjects was 0.53 units ( $95 \%$ confidence interval (CI) 0.34 to 0.72 ). The standardised mean difference in the fibrinogen level was 0.47 units $(95 \% \mathrm{Cl} 0.29$ to 0.65 ). Circulating leucocytes were also higher in COPD than in control subjects (standardised mean difference 0.44 units $(95 \% \mathrm{Cl} 0.20$ to 0.67$)$ ), as were serum TNF- $\alpha$ levels (standardised mean difference 0.59 units $(95 \% \mathrm{Cl}$ 0.29 to 0.89$))$.

Conclusions: Reduced lung function is associated with increased levels of systemic inflammatory markers which may have important pathophysiological and therapeutic implications for subjects with stable COPD.
S ystemic inflammation is increasingly being recognised as a risk factor for a number of different complications including atherosclerosis, ${ }^{1}$ cachexia, ${ }^{2}$ anorexia, ${ }^{2}{ }^{3}$ and osteoporosis. ${ }^{4}$ Notably, all of these complications are commonly observed in patients with chronic obstructive pulmonary disease (COPD). ${ }^{5-10}$ Whether systemic inflammation is present in stable COPD and whether it is wholly or partially responsible for these associations is controversial. Although several studies have been undertaken to evaluate this potential relationship, most of the studies have been small in size and scope and, as such, may on their own have lacked sufficient statistical power to address this issue adequately. To overcome these and other limitations and to understand better the relationship between COPD and systemic inflammation, we conducted a systematic review and meta-analysis with the specific aim of examining the associations between stable COPD and serum levels of C-reactive protein (CRP), fibrinogen, leucocytes, and various proinflammatory cytokines. We chose these markers of systemic inflammation because they have been well studied and have been intimately linked with the development of ischaemic heart disease and stroke ${ }^{11-13}$ which, interestingly, are also the leading causes of mortality among patients with COPD. ${ }^{14}$

\section{METHODS}

\section{Search for relevant studies}

Using MEDLINE (1966-2003), EMBASE, CINAHL (19822003), and the Cochrane databases we conducted a systematic literature search to identify relevant studies published before 1 November 2003 which evaluated the potential relationship between stable COPD and various markers of systemic inflammation. Disease-specific search terms (COPD, bronchitis, emphysema, forced expiratory volume, or vital capacity) were combined with inflammatory marker-specific search terms (systemic inflammation, biological markers, Creactive protein, fibrinogen, leucocyte, interleukin, interleukin-8, interleukin-6, or tumour necrosis factor- $\alpha$ ) in all our searches. The electronic searches were supplemented by scanning the reference lists from retrieved articles to identify additional studies that may have been missed during the initial search. We also contacted the primary authors for additional data and/or clarification of data, when necessary, to ensure that all relevant articles were represented in the meta-analysis. It was decided a priori to include only those studies in which stable patients (or individuals) were studied. All acute exacerbation studies were therefore discarded, as were those that did not have a suitable comparator group.

\section{Study selection and data abstraction}

The primary outcome of this systematic review was to compare serum CRP, fibrinogen, leucocyte, tumour necrosis factor (TNF)- $\alpha$, interleukin 6 (IL-6), and interleukin 8 (IL-8) levels between study participants with and without stable COPD. From each relevant article two investigators (WQG, DDS) abstracted the following information: source of the data, study design, baseline characteristics of study participants including age, predicted forced expiratory volume in l second $\left(F E V_{1}\right)$, and smoking status. We also evaluated the laboratory methods used to determine the levels of systemic inflammatory markers. Any questions or discrepancies regarding these data were resolved through iteration and

Abbreviations: COPD, chronic obstructive pulmonary disease; CRP, Creactive protein; $\mathrm{FEV}_{1}$, forced expiratory volume in 1 second; IL, interleukin; TNF- $\alpha$, tumour necrosis factor- $\alpha$ 
consensus. We used the definition of COPD provided by each individual study, however they were defined. Although there was some heterogeneity in the way in which COPD was defined across the studies, most defined COPD using spirometric criteria of $\mathrm{FEV}_{1} /$ forced vital capacity (FVC) $<0.70$ or $<0.60$. For population based studies in which COPD was not explicitly defined, we assumed that participants in the lowest quartile group of predicted $\mathrm{FEV}_{1}$ had COPD while those in the highest quartile group of predicted $\mathrm{FEV}_{1}$ did not (and therefore served as controls). We assumed that most individuals in the former category had COPD since, from a population perspective, COPD is the most common cause of chronic airflow limitation in the adult population. For these studies we included data only from those participants who had a history of smoking; data from lifetime non-smokers were censored from the main analyses. Studies which did not provide spirometric data on the study participants were excluded to ensure comparability of the COPD definition across the studies.

\section{Statistical methods}

To accommodate differences in the way in which inflammatory markers were measured and reported across various laboratories, the absolute levels of the above inflammatory markers were converted into a common unit by calculating standardised effect sizes. Standardised effect sizes were derived by dividing the mean difference in CRP levels between COPD and control subjects of each study by its standard deviation. ${ }^{15}$ The same technique was used to calculate standardised mean differences for leucocytes, fibrinogen, and other inflammatory cytokines. For each outcome we tested the heterogeneity of results across the studies using a Cochran Q test. If significant heterogeneity was observed $(p<0.10)$, a random effects model-which assigns a weight to each study based on individual study variance as well as between study variance-was used to pool the results together. In the absence of significant heterogeneity a fixed effects model was used. ${ }^{16}$ As a sensitivity analysis we also pooled the data together using a weighted mean difference technique. All analyses were conducted using Review Manager version 4.2 (Revman; The Cochrane Collaboration, Oxford, UK).

\section{RESULTS}

A summary of the search strategy is shown in fig 1 . The original search yielded 911, 666, 279, and 16 citations in MEDLINE, EMBASE, CINAHL, and the Cochrane Databases, respectively. The abstracts of these articles were selected and reviewed. Of these, 19 articles were retrieved for a detailed review: seven for $\mathrm{CRP}{ }^{17-23}$ six for fibrinogen, ${ }^{17}{ }^{20}{ }^{24-27}$ six for leucocytes, ${ }^{17} 182028-30$ six for TNF- $\alpha,{ }^{22}{ }^{31-35}$ two for IL-6, ${ }^{22}{ }^{23}$ and two for IL-8. ${ }^{23} 35$ Five studies were excluded for the following reasons: two studies were publications of the same cohort; ${ }^{17}{ }^{34}$ two provided data on leucocytes based only on a linear regression model which made it impossible to ascertain the relationship between COPD and leucocytes, ${ }^{28}{ }^{30}$ and one study diagnosed chronic bronchitis based only on symptoms (without spirometry). ${ }^{27}$ This process left 14 original studies meeting the inclusion and exclusion criteria which were then used for the analyses: five for CRP, ${ }^{18-22}$ four for fibrinogen, ${ }^{20}{ }^{24-26}$ four for TNF- $\alpha,{ }^{22}{ }^{31-33}$ three for leucocytes, ${ }^{18} 2029$ two for IL- $8,{ }^{23}{ }^{35}$ and one for IL- $6 .{ }^{22}$ The relevant baseline data from each of the selected studies are summarised in table 1 .

Patients with COPD had higher levels of CRP than control subjects in all studies. Overall, the standardised mean difference in the CRP level between COPD and control subjects was 0.53 units $(95 \%$ CI 0.34 to 0.72 ; fig 2 ) or $1.86 \mathrm{mg} / \mathrm{l}$ (95\% CI 0.75 to 2.97 ) using a weighted mean difference technique. The heterogeneity in results across the

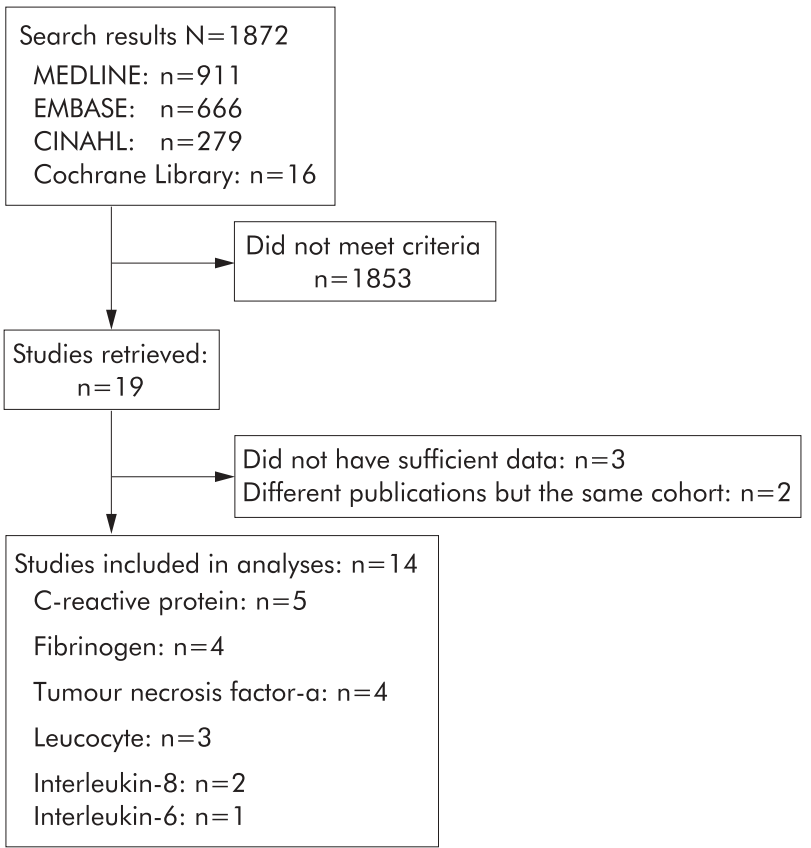

Figure 1 Study selection process.

studies (test for heterogeneity, $\mathrm{p}=0.006$ ) probably resulted from differences in severity of the underlying COPD population and ways in which control subjects were selected for each study. Mannino et $a^{20}$ and Mendall et al, ${ }^{21}$ for instance, used data from a population based study whereas Eid et al ${ }^{19}$ and Yasuda et al ${ }^{22}$ recruited their patients from respiratory clinics. Not surprisingly, the standardised mean difference values in CRP were larger in the latter studies than the former. Importantly, however, even in population based studies, which are less susceptible to selection bias, a strong relationship was observed between CRP and COPD which suggests that COPD is, indeed, a risk factor for increased CRP in the community.

Similarly, patients with COPD had higher fibrinogen levels than control subjects. Overall, the standardised mean difference in the fibrinogen level was 0.47 units (95\% CI 0.29 to 0.65 , fig 3 ) or $0.37 \mathrm{~g} / \mathrm{l}$ (95\% CI 0.18 to 0.56 ) using a weighted mean difference technique. As with the CRP results, there was some heterogeneity in the results between the studies (test for heterogeneity, $\mathrm{p}<0.0001$ ). However, all studies (both large and small) showed that fibrinogen levels were higher in COPD than in control subjects. For population based studies ${ }^{2025} 26$ the standardised mean difference between the lowest quartile group and the highest quartile group of predicted $\mathrm{FEV}_{1}$ among smokers was 0.43 units (95\% CI 0.24 to 0.61$) .2526$

Overall, circulating leucocytes were higher in patients with COPD than in control subjects. The standardised mean difference was 0.44 units ( $95 \%$ CI 0.20 to 0.67 ; test for heterogeneity, $\mathrm{p}=0.003$ ) or $0.88 \times 10^{9}$ cells/l (95\% CI 0.36 to 1.40) using a weighted mean difference technique (fig 4). Likewise, serum TNF- $\alpha$ levels were higher in patients with COPD than in control subjects. The standardised mean difference was 0.59 units (95\% CI 0.29 to 0.89 ; test for heterogeneity, $\mathrm{p}=0.87$ ) or $2.64 \mathrm{pg} / \mathrm{ml}(95 \% \mathrm{CI}-0.44$ to 5.72$)$ using a weighted mean difference technique (fig 5).

There was only one study with analysable data for IL- $6 .^{22}$ Compared with healthy controls $(\mathrm{N}=22)$, patients with COPD $(\mathrm{N}=39)$ had significantly raised serum levels of IL-6 (mean difference $13.10 \mathrm{pg} / \mathrm{ml} ; 95 \%$ CI 7.23 to 18.97 ). 

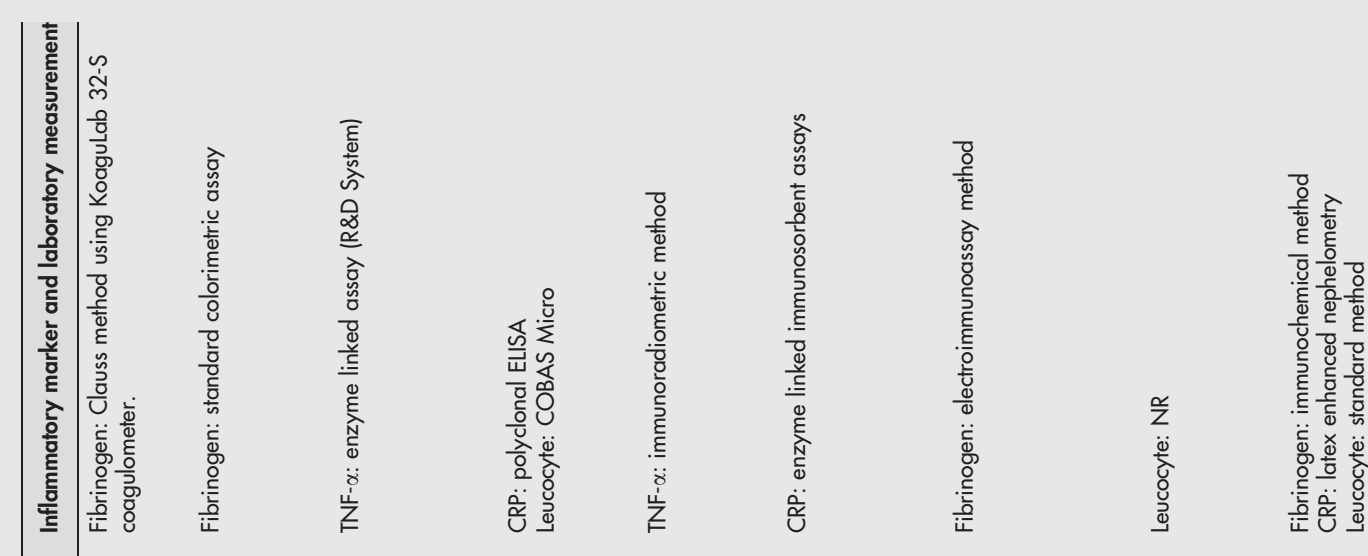

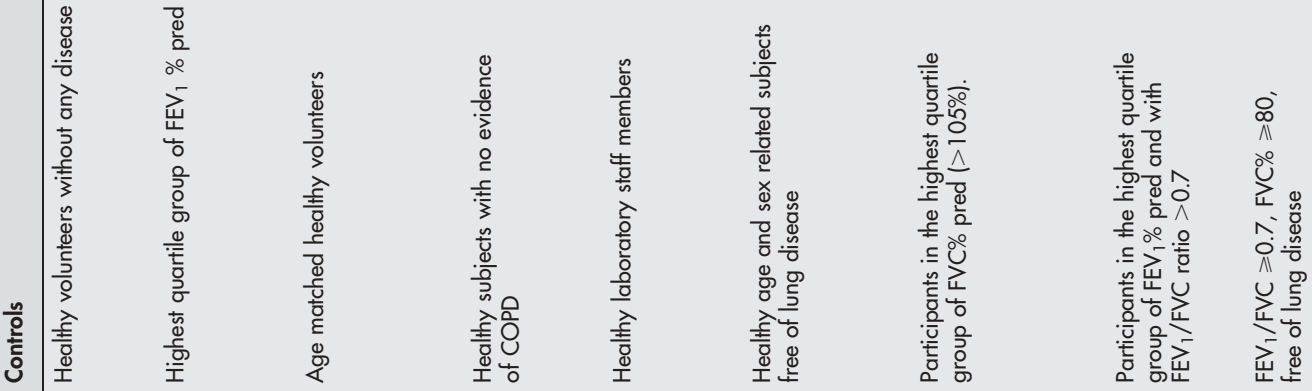

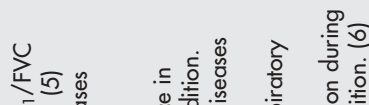

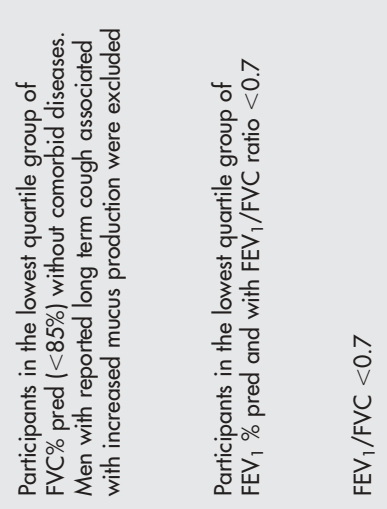

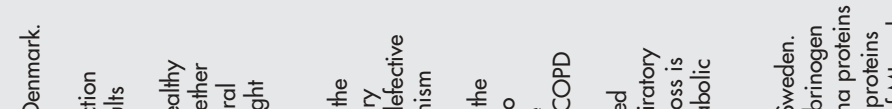




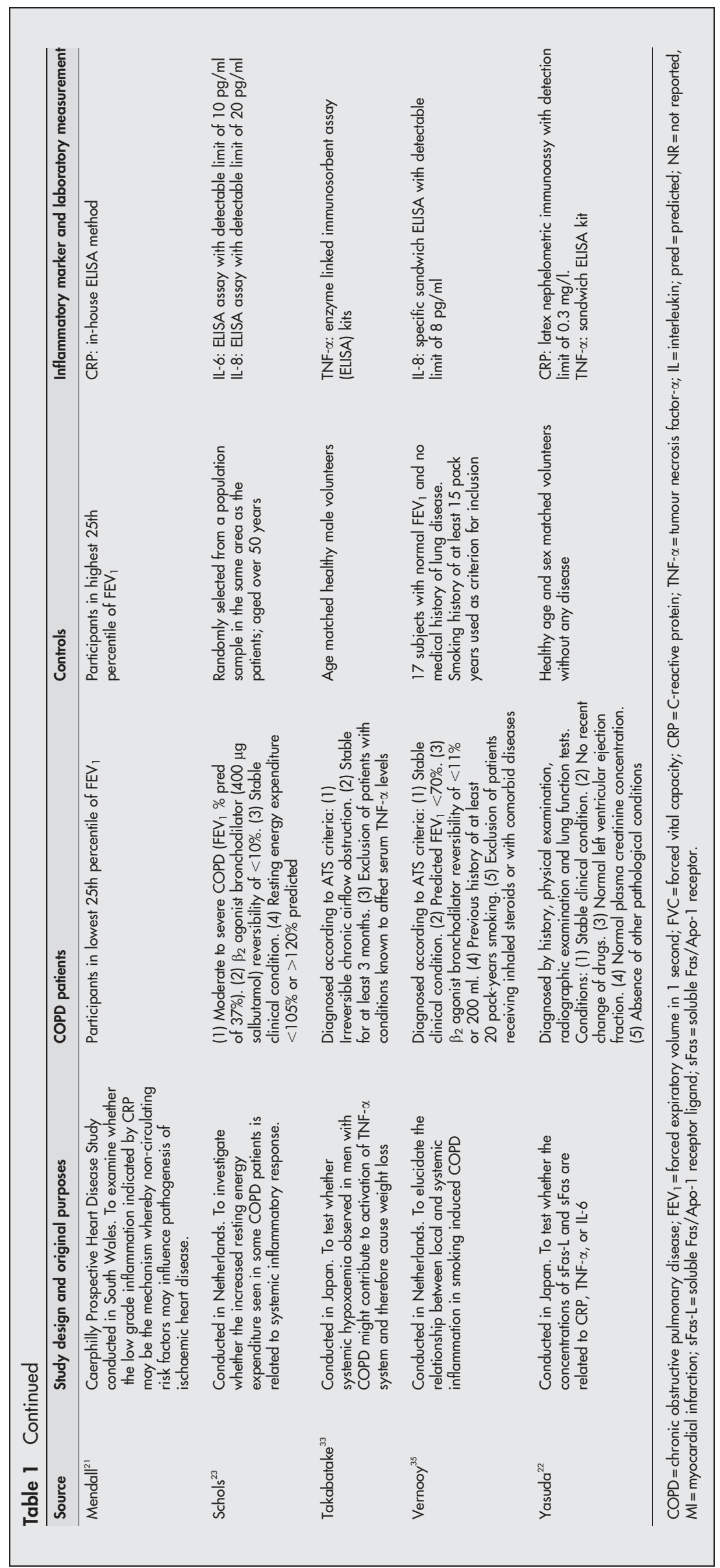




\begin{tabular}{|c|c|c|c|c|c|c|c|}
\hline Author & Group & $\mathbf{N}$ & $\begin{array}{l}\text { Age } \\
(\mathbf{y r})\end{array}$ & $\begin{array}{c}\text { FEV }_{1} \\
\text { (\% pred) }\end{array}$ & $\begin{array}{c}\text { Current } \\
\text { smoker } \\
(\%)\end{array}$ & $\begin{array}{c}\text { Men } \\
(\%)\end{array}$ & $\begin{array}{c}\text { CRP } \\
\text { (mg/l) }\end{array}$ \\
\hline Dentener $^{18}$ & $\begin{array}{l}\text { COPD } \\
\text { Control }\end{array}$ & $\begin{array}{l}55 \\
23\end{array}$ & $\begin{array}{l}69(4) \\
64(3)\end{array}$ & $\begin{array}{c}36(14) \\
110(17)\end{array}$ & $\begin{array}{l}\text { NR } \\
\text { NR }\end{array}$ & $\begin{array}{c}100 \\
70\end{array}$ & $\begin{array}{c}20.4(21.1) \\
9.0(16.0)\end{array}$ \\
\hline $\mathrm{Eid}^{19}$ & $\begin{array}{l}\text { COPD } \\
\text { Control }\end{array}$ & $\begin{array}{l}68 \\
45\end{array}$ & $\begin{array}{c}68(7) \\
\text { NR }\end{array}$ & $\begin{array}{c}31(8) \\
\text { NR }\end{array}$ & $\begin{array}{c}100 \\
33\end{array}$ & $\begin{array}{l}57 \\
\text { NR }\end{array}$ & $\begin{array}{l}3.5(3.4) \\
3.1(1.9)\end{array}$ \\
\hline Mannino ${ }^{20}$ & $\begin{array}{l}\text { COPD } \\
\text { Control }\end{array}$ & $\begin{array}{l}2366 \\
8446\end{array}$ & $\begin{array}{l}64(16) \\
40(17)\end{array}$ & $\begin{array}{c}78(20) \\
103(13)\end{array}$ & $\begin{array}{l}32 \\
21\end{array}$ & $\begin{array}{l}60 \\
48\end{array}$ & $\begin{array}{l}3.3(2.0) \\
2.7(1.0)\end{array}$ \\
\hline Mendall $^{21}$ & $\begin{array}{l}\text { COPD } \\
\text { Control }\end{array}$ & $\begin{array}{l}349^{*} \\
349^{*}\end{array}$ & $\begin{array}{l}45-59 \\
45-59\end{array}$ & $\begin{array}{l}N R \\
\text { NR }\end{array}$ & $\begin{array}{l}N R \\
N R\end{array}$ & $\begin{array}{l}100 \\
100\end{array}$ & $\begin{array}{c}0.8(2.8)^{*} \\
0(0)\end{array}$ \\
\hline Yasuda $^{22}$ & $\begin{array}{l}\text { COPD } \\
\text { Control }\end{array}$ & $\begin{array}{l}39 \\
22\end{array}$ & $\begin{array}{l}66(3) \\
66(1)\end{array}$ & $\begin{array}{l}35(1) \\
82(0)\end{array}$ & $\begin{array}{l}41 \\
32\end{array}$ & $\begin{array}{l}69 \\
68\end{array}$ & $\begin{array}{c}18.7(17.8) \\
0.9(2.8)\end{array}$ \\
\hline
\end{tabular}

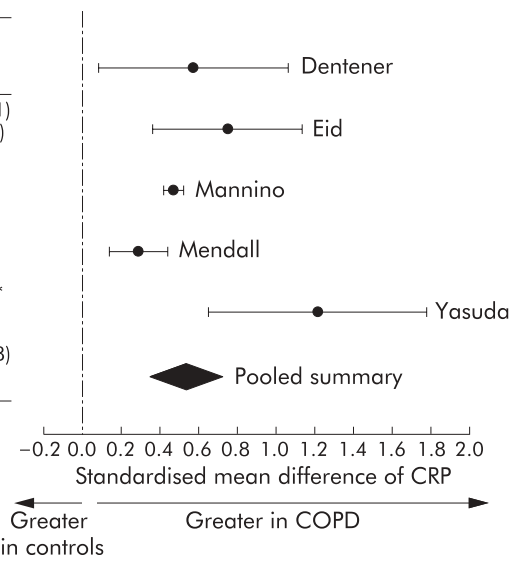

Figure 2 Relationship between C-reactive protein (CRP) and COPD. Continuous variables are expressed as mean (SD) unless otherwise specified. *Imputed from the regression coefficient between mean FEV 1 (25-75th percentile) and CRP.

\begin{tabular}{lccccccc}
\hline Author & Group & $\mathbf{N}$ & $\begin{array}{c}\text { Age } \\
(\mathbf{y r})\end{array}$ & $\begin{array}{c}\mathrm{FEV}_{1} \\
(\% \text { pred) }\end{array}$ & $\begin{array}{c}\text { Current } \\
\text { smoker } \\
(\%)\end{array}$ & $\begin{array}{c}\text { Men } \\
(\%)\end{array}$ & $\begin{array}{c}\text { Fibrinogen } \\
(\mathbf{g} / \mathbf{l})\end{array}$ \\
\hline Alessandri24 $^{24}$ & COPD & 37 & $68(8)$ & $1.1(0.5)^{*}$ & 19 & 73 & $3.0(0.9)$ \\
& Control & 30 & $58(10)$ & $\mathrm{NR}$ & 20 & 70 & $2.3(0.5)$ \\
Dahl25 $^{25}$ & COPD & 1427 & $62(12)$ & $66(15)$ & 100 & 51 & $3.5(1.0)$ \\
Smokers & Control & 785 & $55(15)$ & $117(9)$ & 100 & 43 & $3.0(0.8)$ \\
Engstrom $^{226}$ & COPD & 720 & $47(4) \neq$ & $<85$ & 100 & $\mathrm{NR}$ & $3.8(0.9)$ \\
Smokers $^{2}$ & Control & 449 & $47(4) \neq$ & $>105$ & 100 & $\mathrm{NR}$ & $3.6(0.8)$ \\
Mannino $^{20}$ & COPD & 2065 & $67(12)$ & $77(21)$ & 31 & 60 & $3.1(0.6)$ \\
& Control & 3488 & $57(13)$ & $104(14)$ & 17 & 47 & $2.8(0.5)$ \\
\hline
\end{tabular}
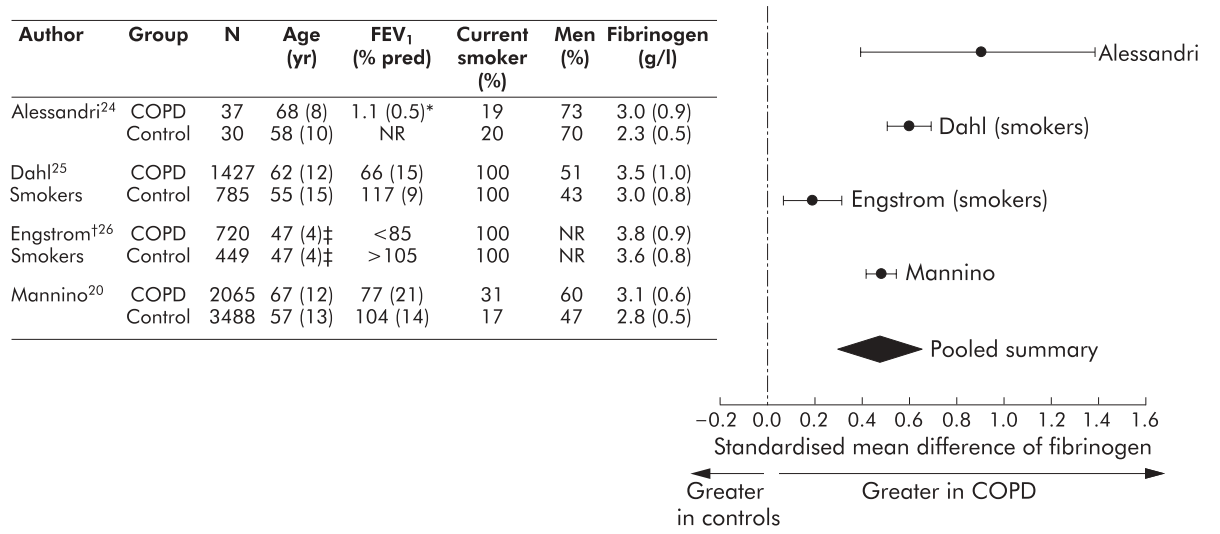

Figure 3 Relationship between fibrinogen and COPD. Continuous variables are expressed as mean (SD) unless otherwise specified. ${ }^{*} \mathrm{FEV} \mathrm{V}_{1}$ in litres. †Based on forced vital capacity. $\ddagger$ Estimated.

There were two studies on IL- $8 .{ }^{23} 35$ One study showed that 17 of 30 patients with COPD had a detectable IL-8 level whereas none of the 26 healthy controls had detectable serum IL-8 (using an assay with a detectable limit of $20 \mathrm{pg}$ / $\mathrm{ml}){ }^{23}$ Another study reported that four out of 18 patients with COPD had detectable IL-8 levels in their serum compared with none of 17 healthy controls (using an assay with detectable limit of $8 \mathrm{pg} / \mathrm{ml}){ }^{35}$

\section{DISCUSSION}

In this systematic review we found that, compared with healthy controls, individuals with chronic airflow limitation had significantly raised levels of CRP, fibrinogen, leucocytes, and TNF- $\alpha$, indicating that persistent systemic inflammation is present in COPD. Even among non-current smokers there was evidence for low grade systemic inflammation in those with chronic airflow limitation. This suggests that, once

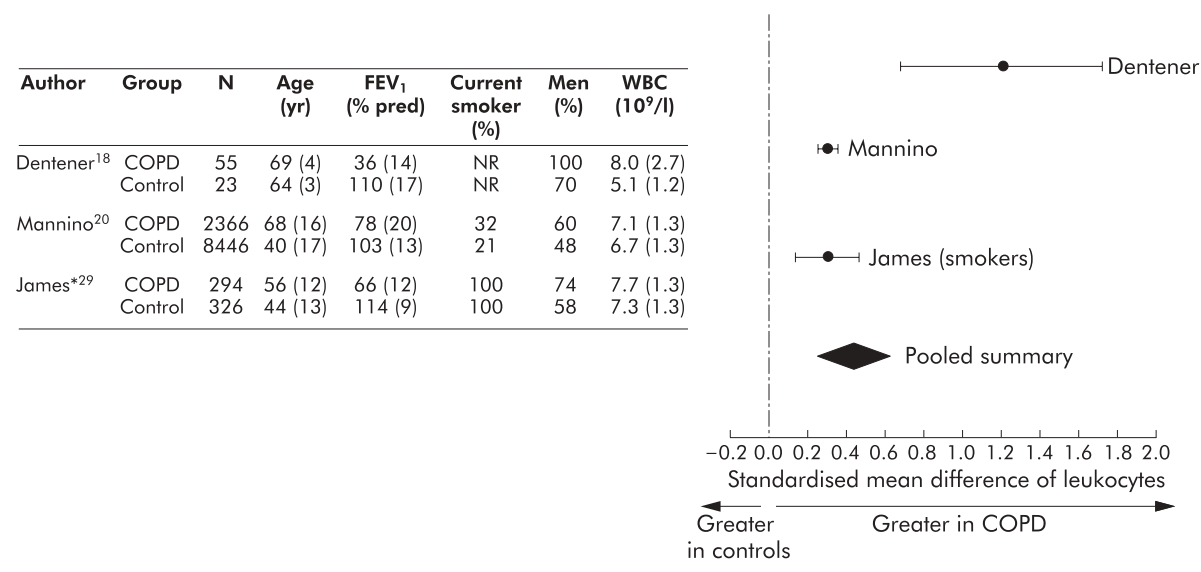

Figure 4 Relationship between leucocytes and COPD. Continuous variables are expressed as mean (SD) unless otherwise specified. *Data from smokers only. WBC $=$ white blood cells. 


\begin{tabular}{llcccccc}
\hline Author & Group & $\mathbf{N}$ & $\begin{array}{c}\text { Age } \\
(\mathbf{y r})\end{array}$ & $\begin{array}{c}\mathrm{FEV}_{1} \\
(\% \text { pred) }\end{array}$ & $\begin{array}{c}\text { Current } \\
\text { smoker } \\
(\%)\end{array}$ & $\begin{array}{c}\text { Men } \\
(\%)\end{array}$ & $\begin{array}{c}\text { TNF-a } \\
(\mathbf{p g} / \mathbf{m l})\end{array}$ \\
\hline de Godoy $^{31}$ & COPD & 20 & $69(9)$ & $69(13)$ & $\mathrm{NR}$ & 70 & $7.0(2.9)^{\dagger}$ \\
& Control & 13 & $64(6)$ & $106(17)$ & $\mathrm{NR}$ & 85 & $5.8(1.5)^{\dagger}$ \\
Di Francia $^{32}$ & COPD & 30 & $65(9)$ & $0.4(0.1)^{*}$ & $\mathrm{NR}$ & 100 & $40.6(73.1)$ \\
& Control & 21 & $47(13)$ & $\mathrm{NR}$ & $\mathrm{NR}$ & 100 & $7.8(3.9)$ \\
Takabatake $^{33}$ & COPD & 27 & $73(7)$ & $52(20)$ & $\mathrm{NR}$ & 100 & $6.2(1.1)$ \\
& Control & 15 & $70(6)$ & $74(7)$ & $\mathrm{NR}$ & 100 & $5.4(1.6)$ \\
Yasuda $^{22}$ & COPD & 39 & $66(3)$ & $35(1)$ & 41 & 69 & $21.8(33.6)$ \\
& Control & 22 & $66(1)$ & $82(0)$ & 30 & 68 & $3.9(2.4)$ \\
\hline
\end{tabular}
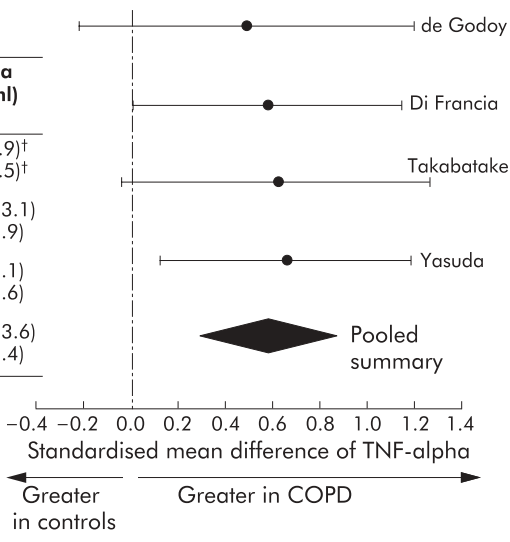

Figure 5 Relationship of tumour necrosis factor- $\alpha$ and COPD. * $\mathrm{FEV}_{1} / \mathrm{FVC}$. †Deduced from medians and ranges.

COPD develops, cessation of smoking may not fully attenuate the inflammatory process associated with this condition.

How and why individuals with COPD develop systemic inflammation is uncertain and unknown. COPD is characterised by an intense inflammatory process in the airways, parenchyma, and pulmonary vasculature. ${ }^{36}$ It is possible in some cases that the inflammatory process may "spill" over into the systemic circulation, promoting a generalised inflammatory reaction. ${ }^{37-40}$ It is also possible that there are common genetic or constitutional factors that may predispose individuals with COPD to both systemic and pulmonary inflammation. ${ }^{36}{ }^{41}$ Furthermore, while we believe that COPD is responsible for the systemic inflammation, there exists the possibility of reverse causation. The possibility that systemic inflammation causes injuries to the airways leading to COPD changes cannot be fully discounted. ${ }^{25}$

Whatever the mechanism, the presence of systemic inflammation in COPD has been linked with a variety of complications including weight loss, ${ }^{19} 3132$ cachexia, ${ }^{8}{ }^{10}$ osteoporosis, ${ }^{10}$ and cardiovascular diseases..$^{5-7}$ Moreover, data from Dahl et al suggest that individuals with increased systemic inflammatory markers such as fibrinogen experience an accelerated decline in lung function and are at increased risk of COPD hospitalisations in the future. ${ }^{25}$ The relationship between COPD, systemic inflammation, and cardiovascular diseases may be especially germane as over half of patients with COPD die from cardiovascular causes. ${ }^{42} 43$ Indeed, airflow limitation doubles the risk of cardiovascular mortality independent of smoking. ${ }^{5-7} 1726$ Moreover, during periods of exacerbation, plasma levels of fibrinogen and serum levels of IL-6 increase significantly, which may further contribute to increased cardiovascular morbidity and mortality in patients with COPD. ${ }^{44}$

Several limitations of this study should be emphasised. Firstly, all relevant studies regarding the association between impaired lung function and systemic inflammation were cross sectional in nature, so the temporal relationships between these two factors were unclear. Secondly, there was some variation in the way in which inflammatory markers were sampled and analysed. There was also heterogeneity in the sample populations across the studies. Even within the COPD group, some were selected on the basis of weight loss or poor nutritional status and, as such, may not represent the general pool of COPD patients. However, despite these variations, it was reassuring that in nearly all studies (regardless of sample size, baseline $\mathrm{FEV}_{1}$, and composition of the study and control groups), those with airflow limitation had, on average, higher levels of systemic inflammatory markers than healthy controls. This suggests that selection and sampling biases were unlikely to be responsible for the observed associations. Thirdly, there was a marked paucity of studies that evaluated the relationship between COPD and IL- 6 or IL-8. IL- 6 has been implicated in the pathogenesis of atherosclerosis ${ }^{45-47}$ while IL-8 may be an important signalling molecule for neutrophils which may have significance in the pathophysiology of COPD. ${ }^{48}{ }^{49}$ In view of their potential relevance in COPD, more studies are needed in the future to determine whether the systemic expression of these cytokines is increased in COPD.

In summary, there is now a large body of evidence to indicate that systemic inflammation is present in patients with stable COPD. This finding may explain, at least in part, the high prevalence of systemic complications such as cachexia, osteoporosis, and cardiovascular diseases among patients with COPD. Future studies are needed to determine whether attenuation of the systemic inflammatory process can modify the risk of these complications in COPD.

\section{ACKNOWLEDGEMENTS}

The authors thank Dr Morten Dahl, Dr Matthew Knuiman and the Busselton Health Study, and Dr Mieke Dentener for providing additional data for this study.

\section{Authors' affiliations}

S F P Man, D D Sin, The James Hogg iCAPTURE Center for Cardiovascular and Pulmonary Research, Vancouver, British Columbia, Canada

S F P Man, D D Sin, Department of Medicine (Pulmonary Division), University of British Columbia, Vancouver, British Columbia, Canada W Q Gan, Department of Medicine, Pulmonary Division, University of Alberta, Edmonton, Alberta, Canada

A Senthilselvan, Department of Public Health Sciences, University of Alberta, Edmonton, Alberta, Canada

DDS is supported by a New Investigator Award from the Canadian Institutes of Health Research and by the Glaxo-Smith-Kline/St Paul's Hospital Foundation COPD Professorship

\section{REFERENCES}

1 Ross R. Atherosclerosis: an inflammatory disease. N Engl J Med 1999;340:115-26.

2 Kotler DP. Cachexia. Ann Intern Med 2000;133:622-34.

3 Johnson PM, Vogt SK, Burney MW, et al. COX-2 inhibition attenuates anorexia during systemic inflammation without impairing cytokine production. Am J Physiol Endocrinol Metab 2002;282:650-6.

4 Raisz LG. Physiology and pathophysiology of bone remodeling. Clin Chem 1999:45:1353-8.

5 Schunemann HJ, Dorn J, Grant BJ, et al. Pulmonary function is a long-term predictor of mortality in the general population: 29-year follow-up of the Buffalo Health Study. Chest 2000; 1 18:656-64.

6 Hole DJ, Watt GC, Davey-Smith G, et al. Impaired lung function and mortality risk in men and women: findings from the Renfrew and Paisley prospective population study. BMJ 1996;313:711-5.

7 Friedman GD, Klatsky AL, Siegelaub AB. Lung function and risk of myocardial infarction and sudden cardiac death. N Engl J Med 1976;294:1071-5. 
8 Schols AM. Pulmonary cachexia. Int J Cardiol 2002:85:101-10.

9 Biskobing DM. COPD and osteoporosis. Chest 2002;121:609-20.

10 Agusti AG, Noguera A, Sauleda J, et al. Systemic effects of chronic obstructive pulmonary disease. Eur Respir J 2003;21:347-60.

11 Danesh J, Collins R, Appleby P, et al. Association of fibrinogen, C-reactive protein, albumin, or leukocyte count with coronary heart disease: metaanalyses of prospective studies. JAMA 1998;279:1477-82.

12 Pradhan AD, Manson JE, Rossouw JE, et al. Inflammatory biomarkers, hormone replacement therapy, and incident coronary heart disease: prospective analysis from the Women's Health Initiative observational study. JAMA 2002;288:980-7.

13 Di Napoli M, Papa F, Bocola V. Prognostic influence of increased C-reactive protein and fibrinogen levels in ischemic stroke. Stroke 2001;3:133-8.

14 Hansell AL, Walk JA, Soriano JB. What do chronic obstructive pulmonary disease patients die from? A multiple cause coding analysis. Eur Respir J 2003;22:809-14.

15 Curtin F, Altman DG, Elbourne D. Meta-analysis combining parallel and cross-over clinical trials. I: Continuous outcomes. Stat Med 2002;21:2131-44.

16 DerSimonian R, Laird N. Meta-analysis in clinical trials. Control Clin Trials 1986:7:177-88.

17 Sin DD, Man SF. Why are patients with chronic obstructive pulmonary disease at increased risk of cardiovascular diseases? The potential role of systemic inflammation in chronic obstructive pulmonary disease. Circulation 2003;107:1514-9.

18 Dentener MA, Creutzberg EC, Schols AM, et al. Systemic anti-inflammatory mediators in COPD: increase in soluble interleukin 1 receptor II during treatment of exacerbations. Thorax 2001;56:721-6.

19 Eid AA, lonescu AA, Nixon LS, et al. Inflammatory response and body composition in chronic obstructive pulmonary disease. Am J Respir Crit Care Med 2001; 164:1414-8.

20 Mannino DM, Ford ES, Redd SC. Obstructive and restrictive lung disease and markers of inflammation: Data from the third national health and nutrition examination. Am J Med 2003;114:758-62.

21 Mendall MA, Strachan DP, Butland BK, et al. C-reactive protein: relation to total mortality, cardiovascular mortality and cardiovascular risk factors in men. Eur Heart J 2000;21:1584-90.

22 Yasuda N, Gotoh K, Minatoguchi S, et al. An increase of soluble Fas, an inhibitor of apoptosis, associated with progression of COPD. Respir Med 1998;92:993-9.

23 Schols AM, Buurman WA, Staal van den Brekel AJ, et al. Evidence for a relation between metabolic derangements and increased levels of inflammatory mediators in a subgroup of patients with chronic obstructive pulmonary disease. Thorax 1996;51:819-24.

24 Alessandri C, Basili S, Violi F, et al. Hypercoagulability state in patients with chronic obstructive pulmonary disease. Chronic Obstructive Bronchitis and Haemostasis Group. Thromb Haemost 1994;72:343-6.

25 Dahl M, Tybjaerg-Hansen A, Vestbo J, et al. Elevated plasma fibrinogen associated with reduced pulmonary function and increased risk of chronic obstructive pulmonary disease. Am J Respir Crit Care Med 2001;164:1008-11.

26 Engstrom G, Lind P, Hedblad B, et al. Lung function and cardiovascular risk: relationship with inflammation-sensitive plasma proteins. Circulation 2002; 106:2555-60

27 Jousilahti P, Salomaa V, Rasi V, et al. Symptoms of chronic bronchitis, haemostatic factors, and coronary heart disease risk. Atherosclerosis 1999; 142:403-7.

28 Bridges RB, Wyatt RJ, Rehm SR. Effects of smoking on inflammatory mediators and their relationship to pulmonary dysfunction. Eur J Respir Dis Suppl $1986 ; 146: 145-52$.
29 James AL, Knuiman MW, Divitini ML, et al. Associations between white blood cell count, lung function, respiratory illness and mortality: the Busselton Health Study. Eur Respir J 1999;13:11115-9.

30 Yeung MC, Buncio AD. Leukocyte count, smoking, and lung function. Am J Med 1984;76:31-7.

31 de Godoy I, Donahoe M, Calhoun WJ, et al. Elevated TNF- $\alpha$ production by peripheral blood monocytes of weight-losing COPD patients. Am J Respir Crit Care Med 1996;153:633-7.

32 Di Francia M, Barbier D, Mege JL, et al. Tumor necrosis factor levels and weight loss in chronic obstructive pulmonary disease. Am J Respir Crit Care Med 1994; 150:1453-5.

33 Takabatake N, Nakamura H, Abe S, et al. The relationship between chronic hypoxemia and activation of the tumor necrosis factor-alpha system in patients with chronic obstructive pulmonary disease. Am J Respir Crit Care Med 2000;161:1179-84.

34 Takabatake N, Nakamura H, Abe S, et al. Circulating leptin in patients with chronic obstructive pulmonary disease. Am J Respir Crit Care Med 1999; 159:1215-9

35 Vernooy JH, Kucukaycan M, Jacobs JA, et al. Local and systemic inflammation in patients with chronic obstructive pulmonary disease: soluble tumor necrosis factor receptors are increased in sputum. Am J Respir Crit Care Med 2002; 166:1218-24.

36 Pauwels RA, Buist AS, Calverley PM, et al. Global strategy for the diagnosis, management, and prevention of chronic obstructive pulmonary disease: NHLBI/WHO Global Initiative for Chronic Obstructive Lung Disease (GOLD) Workshop summary. Am J Respir Crit Care Med 2001;163:1256-76.

37 van Eeden SF, Tan WC, Suwa T, et al. Cytokines involved in the systemic inflammatory response induced by exposure to particulate matter air pollutants (PM 10). Am J Respir Crit Care Med 2001;164:826-30.

38 Fujii T, Hayashi S, Hogg JC, et al. Interaction of alveolar macrophages and airway epithelial cells following exposure to particulate matter produces mediators that stimulate the bone marrow. Am J Respir Cell Mol Biol 2002;27:34-41.

39 Tan WC, Qui D, Liam BL, et al. The human bone marrow response to fine particulate air pollution. Am J Respir Crit Care Med 2000;161:1213-7.

40 Salvi S, Blomberg A, Rudell B, et al. Acute inflammatory responses in the airways and peripheral blood after short-term exposure to diesel exhaust in healthy human volunteers. Am J Respir Crit Care Med 1999;159:702-9.

41 Barnes PJ. Chronic obstructive pulmonary disease. N Engl J Med 2000;343:269-80.

42 Anthonisen NR, Connett JE, Kiley JP, et al. Effects of smoking intervention and the use of an inhaled anticholinergic bronchodilator on the rate of decline FEV $_{1}$. The Lung Health Study. JAMA 1994;272:1497-505.

43 Camilli AE, Robbins DR, Lebowitz MD. Death certificate reporting of confirmed airways obstructive disease. Am J Epidemiol 1991;133:795-800.

44 Wedzicha JA, Seemungal TA, MacCallum PK, et al. Acute exacerbations of chronic obstructive pulmonary disease are accompanied by elevations of plasma fibrinogen and serum IL-6 levels. Thromb Haemost 2000;84:210-5.

45 Yudkin JS, Kumari M, Humphries SE, et al. Inflammation, obesity, stress and coronary heart disease: is interleukin-6 the link? Atherosclerosis 2000;148:209-14.

46 Lindmark E, Diderholm E, Wallentin L, et al. Relationship between interleukin 6 and mortality in patients with unstable coronary artery disease: effects of an early invasive or noninvasive strategy. JAMA 2001;286:2107-13.

47 Ridker PM, Rifai N, Stampfer MJ, et al. Plasma concentration of interleukin-6 and the risk of future myocardial infarction among healthy men. Circulation 2000;101:1767-72.

48 Barnes PJ, Shapiro SD, Pauwels RA. Chronic obstructive pulmonary disease: molecular and cellular mechanisms. Eur Respir J 2003;22:672-88.

49 Gabay C, Kushner I. Acute-phase proteins and other systemic responses to inflammation. N Engl J Med 1999;340:448-54. 